\title{
A "foto roubada"- mídias, visibilidade e cidadania da imigração haitiana no Brasil ${ }^{1}$
}

\section{Denise Cogo e Matheus Pássaro}

\section{Resumo}

0 artigo analisa as relações entre produção de imagens, visibilidade midiática e cidadania da imigração haitiana no Brasil. Coletamos em espaços da internet e analisamos os posicionamentos e as disputas em torno de um episódio específico envolvendo a produção e publicação "não consentida" da foto de um imigrante haitiano pelos jornais Agora e Folha de S. Paulo. Orientados teoricamente pelas noções de imagem, visibilidade e cidadania, os resultados obtidos problematizam as relações entre estética e política na ordem de visualidades das migrações contemporâneas e os impactos de uma visibilidade midiática compulsória, a qual destitui de agência os imigrantes e descontextualiza os processos migratórios.

\section{Palavras-Chave}

Mídia. Imigração. Haiti. Visibilidade. Cidadania.

Denise Cogo I denisecogo2@gmail.com Doutora em Ciências da Comunicação pela Universidade de São Paulo - USP, Brasil. Professora Titular do Programa de Pós-Graduação em Comunicação e Práticas de Consumo da Escola Superior de Propaganda e Marketing - ESPM-SP, Brasil. Pesquisadora 1D do CNPq.

Matheus Pássaro I matheuspassaro@gmail.com Mestre em Comunicação e Práticas de Consumo pela Escola Superior de Propaganda e Marketing - ESPM-SP, Brasil. Professor do Curso de Design da ESPM-SP.

\section{Introdução - objetivos e metodologia}

Neste artigo, propomos refletir sobre a produção de imagens e a visibilidade midiática de imigrantes haitianos no Brasil, buscando compreender os impactos dessa visibilidade nos seus processos de inserção e cidadania no novo contexto de imigração. Para isso, analisamos um episódio específico envolvendo a produção e difusão, em 2015, da foto de um imigrante haitiano procedente do estado do Acre, recém-chegado em ônibus à cidade de São Paulo juntamente com um grupo de imigrantes da mesma nacionalidade.

A foto, publicada com a legenda "Haitiano toma banho em mictório", nos jornais Agora e Folha de São Paulo, e replicada em diferentes espaços da internet, foi capturada, em 19 de maio de 2015, em um banheiro da Missão Paz, organização confessional vinculada à Igreja Católica, onde se situa a Casa do Imigrante, espaços que se constituem como os principais centros de acolhida de imigrantes internacionais que chegam à cidade de São Paulo. Posteriormente, em outubro de 2015, a mesma imagem foi vencedora, na 
categoria Fotografia, do Prêmio Vladimir Herzog, um dos mais importantes na área de jornalismo, anistia e direitos humanos do Brasil. ${ }^{2}$ A seguir, reproduzimos a capa da versão impressa do Jornal Agora (FIG. 1), onde foi publicada, inicialmente, a foto do imigrante haitiano.

Figura 1: Capa da versão impressa do Jornal Agora, onde foi publicada a foto premiada do imigrante haitiano

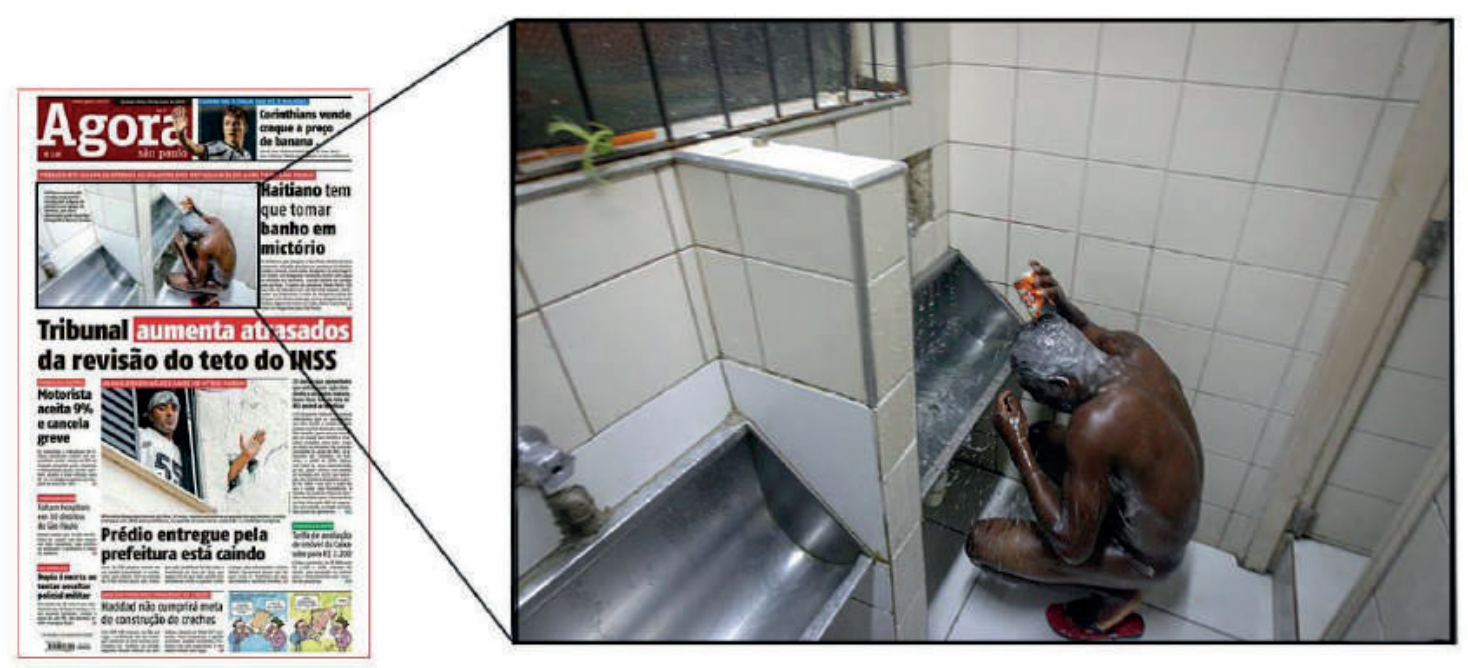

Fonte: Jornal Agora, 19 de maio de 2015.

A captura da imagem, supostamente sem 0 consentimento do imigrante fotografado, e, posteriormente, sua escolha como vencedora do Prêmio Vladimir Herzog, gerou, no âmbito das mídias, um debate público em torno dos impactos dos processos de visibilidade midiática nos direitos humanos e cidadania dos imigrantes haitianos no país.
0 foco de nossa análise são os posicionamentos e as disputas que demarcaram esse debate sobre as repercussões da produção e publicação da "foto roubada", ${ }^{3}$ no qual estiveram implicados a coordenação da Missão Paz, a Organização dos Haitianos em São Paulo, a organização responsável pelo Prêmio Valdimir Herzog, 0 autor da imagem - o fotógrafo Ronny Santos

Versão revisada de artigo apresentado no GT Comunicação e Cidadania do $25^{\circ}$ Congresso Nacional da Compós (Associação Nacional de Programas de Pós-Graduação em Comunicação), realizado de 07 a 10 de junho de 2016, no campus da UFGF, em Goiânia. Artigo resultante de projeto de pesquisa financiado pelo CNPq (Conselho Nacional de Desenvolvimento Científico e Tecnológico).

2 http://www.premiovladimirherzog.org.br/busca-midia.asp?cat=fotos

A expressão "foto roubada" foi utilizada em mensagem de divulgação de petição online contra a publicação da foto que circulou na lista de e-mails da Associação de Estrangeiros e Imigrantes no Brasil. Ver https://br.groups.yahoo.com/neo/ groups/estrangeiros_ANEIB/info 
-, integrantes de redes migratórias e de outras organizações de apoio às migrações do Brasil, comunicadores de mídias alternativas, ${ }^{4}$ assim como indivíduos que interagiram nos espaços digitais de compartilhamento da imagem.

Compreendemos essas disputas em torno da publicação da imagem do imigrante haitiano como um episódio não isolado, mas revelador, de modo mais amplo, de alguns dilemas relacionados aos imbricamentos entre estética e política que demarcam os novos regimes de visualidade da sociedade contemporânea, os quais têm tido incidência nos processos de visibilidade midiática das chamadas minorias, especialmente dos novos grupos migratórios internacionais que chegaram ao Brasil a partir de 2008. 0 episódio é indicativo igualmente da emergência de agenciamentos e ativismos por parte de imigrantes haitianos e suas redes e organizações na perspectiva de reivindicarem 0 direito de intervenção individual e/ou coletiva nos modos de produção midiática de imagens e narrativas sobre suas experiências migratórias e produção de suas próprias políticas de visibilidade midiática.

Em termos metodológicos, a reflexão aqui proposta se constrói a partir da observação, coleta e análise, no período entre maio e outubro de 2015, de narrativas que, em diferentes espaços digitais da internet (portais da grande mídia, sites, redes sociais, blogs, etc.), evidenciaram e compuseram o conjunto de percepções, posicionamentos e disputas de atores que instauraram, nas mídias, um debate em torno da publicação "não consentida" da foto do imigrante haitiano.

\section{Imagem, visibilidade midiática e cidadania das migrações}

Desde a modernidade, as sociedades

contemporâneas vêm experimentando reconfigurações na ordem do intelectivo e do sensível a partir da instauração de um regime de visualidades ancorado na profusão, no excesso e, em alguns casos, na espetacularização, que, em grande medida, decorrem da própria centralidade assumida pelas mídias na vida social. Segundo sintetiza Rocha (2009, p. 35), "[...] excesso rima aqui com anestésico [...] A cultura da visualidade, encantada pela potência da externalização da produção imaginária, pode colocar em risco parte de seu magma de subjetivação e de memória”.

Diferentes teorias do social, conforme retoma García Canclini (2010), reconhecem que os imaginários que derivam da produção, circulação e apropriação das imagens também representam e instituem o social. Conformamos, através das imagens, nossa vida em sociedade e nossa relação com o Outro, o que faz com que "não nos 
movimentemos somente com 0 empiricamente verificável com respeito aos outros, mas também com suposições e conjecturas" (DE LA HABA, SANTAMARIÁ, p. 2001, p. 6) .

Ao sustentar que as imagens são organizadoras de sentidos, Rancière (2012) nos lembra que os sujeitos se subjetivam nas imagens, agregando ao debate a reflexão de que o processo de produção e circulação de imagens está demarcado pela ideia de vínculo indissolúvel entre estética e política. Sempre com a implicação e intervenção dos sujeitos, a estética e a política constituemse, na visão do autor, em maneiras de organizar 0 sensível, ou seja, "de dar a entender, de dar a ver, de construir a visibilidade e a inteligibilidade dos acontecimentos". ${ }^{5}$

A ideia de que a política tem sempre uma dimensão estética, assim como são estéticas as formas de exercício de poder na sociedade, reposiciona o próprio debate em torno da dissociação entre ética e estética no campo da produção midiática e jornalística, o qual também irá demarcar o episódio aqui focalizado de publicação da foto do imigrante haitiano.

Assim, o (re)estabelecimento do vínculo entre estética e política nos informa que não há isenção ou neutralidade possível no processo de produção de visibilidades (BRASIL, MIGLIORIN,
2010), desconstituindo, no caso específico da imagem fotogrática, concepções ainda vigentes entre setores midiáticos e jornalísticos, como a da "fotografia como imagem bruta da realidade", a qual, segundo lembra Machado (2015), só se justificaria em termos estratégicos e ideológicos, sobretudo em uma época em que a comunicação digital se encarregou de instaurar e tornar central um outro regime de experimentação e manipulação técnica das imagens. "A fotografia não pode ser o registro puro e simples de uma imanência do objeto: como produto humano, ela cria também com esses dados luminosos uma realidade e não existe fora dela, mas precisamente nela" (MACHAD0, 2015, p. 48).

Ao lembrar que a câmera nunca é passiva diante de seu objeto, 0 autor preocupa-se, ainda, em enfatizar os arranjos e as configurações que se produzem em função de sua presença, evidenciando que "toda a fotografia, seja qual for 0 referente que a motiva, é sempre um retângulo que recorta o visível [...] evidentemente essa escolha, esse recorte, não são nunca inocentes, nem gratuitos" (MACHADO, 2015, p. 90).

No caso específico da fotografia jornalística, Machado observa, também, que grande parte de seu efeito de "distância" e "objetividade" decorre do ângulo de visão privilegiada assumido pela câmera em relação ao objeto fotografado, ou 
seja, de seu lugar panóptico. Somente esse lugar, de acordo com 0 autor, "é capaz de resolver um problema duplo: possibilitar uma visão abrangente e integral do evento e ao mesmo tempo simular uma posição externa ao evento, como a de um turista visitando a realidade alheia" (MACHADO, 2015, p. 121).

Ainda no caso específico da imagem fotográfica, nos valemos da síntese de Rancière (2012) quando analisa a dupla poética que emerge da fotografia como arte e recurso técnico, conforme nos sugere o próprio episódio de publicação da imagem do imigrante haitiano aqui apresentado. Ou seja, quando a fotografia se torna uma arte e "faz falar duas vezes o rosto dos anônimos", por um lado, "como testemunhas mudas de uma condição inscrita diretamente em seus traços, suas roupas, seus modos de vida"; e, por outro, "como detentores de um segundo que nunca iremos saber, um segredo roubado pela imagem mesma que nos traz esses rostos" (RANCIÈRE, 2012, p. 23-24).

No entanto, 0 atual regime de visualidades das sociedades contemporâneas fundado na profusão das imagens - e que torna 0 tema da ética e do direito à imagem das chamadas minorias ainda mais sensível - alude não apenas ao campo da produção, mas também está condicionado pelas possíveis apropriações e interpretações que se desenrolam na instância do consumo e da recepção das imagens. ${ }^{6}$

"Certas imagens fotográficas parecem injuriar certas pessoas e não outras", ${ }^{7}$ sintetiza Jorge Pedro Sousa, na perspectiva de reiterar que a inevitável polissemia da imagem, sua ambiguidade e pluralidade conceituais, faz com que o sentido último de uma imagem publicada por meios jornalísticos dependa sempre do consumidor da mesma (SOUSA, 2002, p. 136). A dificuldade de interpretar a conotação fotográfica; 0 direcionamento da interpretação da foto pelo contexto em que é apresentada; a tendência de 0 observador enxergar nas fotografias suas próprias projeções, a separação entre fotógrafos e observadores são aspectos que, elencados por Sousa, concorrem, no campo de interpretação da fotografia jornalística. Isso, no entanto, não eximiria de responsabilidade profissional e social os jornalistas ou trabalhadores da mídia que atuam na área da imagem.

No próprio episódio da imagem do imigrante aqui analisada, essa polissemia no âmbito do consumo de imagens pode ser evidenciada em postagens que acompanharam a publicação da foto nas redes sociais e no blog Migramundo. "Não é a mas sim que, conforme os contextos de produção e circulação, ela admite múltiplas e, às vezes, contraditórias leituras.

Poderíamos acrescentar que isso se observa ainda mais em relação às imagens que reportam situações humanitárias, como é o caso da fotografia aqui analisada. 
foto que é desumana. São as condições deles. Se a foto incomodou os pobres olhos sensíveis de vocês, talvez tenha atingido o objetivo principal", se pode ler em uma das postagens na fotografia do haitiano compartilhada no perfil da Folha de S. Paulo no Facebook. ${ }^{8}$ No blog Migramundo, em comentário à entrevista concedida pelo fotógrafo, autor da imagem, um leitor ${ }^{9}$ considera "lamentável" o fotógrafo ter concluído que "os direitos humanos não estavam sendo respeitados (não por negligência da Entidade) ${ }^{10} \mathrm{e}$, sem sensibilidade nenhuma, desrespeitou ainda mais ferindo o imigrante na sua dignidade". 0 leitor destaca, ainda, 0 fato de 0 fotógrafo ter entrado no ambiente "invadindo a privacidade" do imigrante e "ousando fotografá-lo num momento singular e sagrado de sua intimidade, a sua higiene, completando o desrespeito que julgou ter visto, mesmo sabendo de toda a situação e da casa lotada, incapaz de atendê-los".

As pesquisas sobre mídia, migrações transnacionais e cidadania que temos desenvolvido vêm nos possibilitando observar a materialização dessa ordem contemporânea das visualidades em uma hipervisibilização, pelas mídias, das migrações transnacionais, a qual parece guardar uma pretensão narrativa unificadora ao enunciarem, de modo dominante, essa imigração associada a problema, conflito e ameaça e a partir predominantemente de estéticas da espetacularização e do flagrante. ${ }^{11}$

Essa hipervisibilidade tem gerado, no Brasil, um conjunto de reflexões e debates acerca da dimensão política que demarca esse fluxo de imagens e, ao mesmo tempo, sobre as relações entre estética e política na produção midiática a respeito das migrações transnacionais. Imigrantes e suas redes, assim como organizações de apoio às migrações e pesquisadores dedicados à temática têm, por exemplo, se mobilizado para a denúncia pública e desconstituição de imagens criminalizadoras das migrações e para a sensibilização e o comprometimento dos profissionais da comunicação com a ética envolvendo a visibilidade midiática dos imigrantes.

Dessas mobilizações, têm resultado, dentre outras, iniciativas orientadas à problematização da visibilidade midiática das migrações como

Disponível em: https://www.facebook.com/folhadesp/posts/1083527728355896

9 Comentário disponível em: http://migramundo.com/2015/10/22/imagem-de-haitiano-tomando-banho-ganha-premiovladimir-herzog-de-direitos-humanos-entidades-repudiam-e-fotografo-argumenta/

10 Em referência à Missão Paz.

11 Exemplo recente foi a replicação exaustiva da imagem do corpo do menino refugiado sírio Alan al-Kurdi, de três anos de idade, que foi encontrado morto em uma praia da Turquia ao cruzar o Mar Mediterrâneo com a família na tentativa de ingressar na Europa. Ver https://en.wikipedia.org/wiki/Death_of_Alan_Kurdi 
a elaboração e difusão de dois manifestos: ${ }^{12}$

"Manifesto em Defesa dos Direitos Humanos dos Imigrantes Haitianos"13 e "Pela Humanização da Cobertura Midiática da Migração no Brasil". ${ }^{14} \mathrm{E}$, mais recentemente, uma carta enviada ao jornal o Globo pelo pesquisador Helion Póvoa, do Núcleo Interdisciplinar de Estudos Migratórios (NIEM) da Universidade Federal do Rio de Janeiro. ${ }^{15}$ Outra iniciativa foi a publicação do "Guia das Migrações Transnacionais e Diversidade Cultural para Comunicadores - Migrantes no Brasil", elaborado por pesquisadores brasileiros visando à sensibilização e capacitação de jornalistas e comunicadores brasileiros para 0 tema das migrações (COGO, BADET, 2013).

Além disso, tem sido possível observar a instauração, por parte dos próprios imigrantes, de dinâmicas de exercício de uma cidadania comunicativa a partir de iniciativas de criação de espaços comunicacionais contradiscursivos de enunciação de suas experiências migratórias. É 0 caso dos imigrantes haitianos que, em distintos espaços da internet (blogs, sites, redes sociais, etc.), têm se mobilizado para atribuir visibilidade a suas demandas por cidadania, as quais abrangem, dentre outras, questões vinculadas a processos de regularização jurídica, acesso à moradia, saúde, educação e a espaços de lazer e entretenimento, busca de trabalho, envio de remessas aos países de origem, reagrupação familiar e denúncia de situações de racismo.

Tensionados pela exigência de um tipo de visibilidade pública atribuída pelas lógicas midiáticas, os migrantes e suas redes vêm ampliando, através de apropriações e usos da internet, as possibilidades e os lugares de intervenção na cena pública nas esferas locais e para além delas, favorecendo processos de mobilização cidadã também no âmbito de novas esferas públicas transnacionais. São espaços nos quais, como destaca Navarro García (2014), os grupos migrantes e não migrantes podem se reencontrar, compartilhar interesses e valores comuns, assim como propor mobilizações e ações coletivas, conforme foi possível observar no caso da "foto roubada", em que imigrantes haitianos e a Organização de Haitianos de São Paulo intervieram ativamente no debate travado tanto em espaços das mídias como fora dela.

Essas intervenções podem ser situadas, de modo mais amplo, no escopo de um ativismo crescente que, no campo das mídias, vem sendo construído pelos imigrantes haitianos desde sua chegada

12 A coautora deste artigo participou da elaboração desses dois manifestos.

13 http://www. cdhic. org.br/v01/?p=639

14 http://falanegaofalamulher. blogspot.com.br/2013/05/organizacoes-lancam-manifesto-pela.html 
ao Brasil a partir de 2010. Como mapeamos em trabalho anterior (COGO, 2014), no site da rede social Facebook, os imigrantes haitianos se fazem presentes em diversos grupos e perfis. Uma dessas iniciativas, o perfil " 0 que a mídia não mostra do Haiti", criado por um estudante haitiano na cidade de Porto Alegre, sugere 0 esforço de produção de posicionamentos e reflexões frente a imagens midiáticas de pauperização e vitimização do Haiti e dos haitianos que se tornaram dominantes na mídia brasileira após o terremoto naquele país (COG0, 2014) ou, mais recentemente, na denúncia de episódios de discriminação e racismo de que tem sido alvo a imigração haitiana. Na tabela a seguir (FIG. 2), relacionamos alguns desses espaços ocupados pelos imigrantes haitianos no Facebook ${ }^{16}$.

Tabela 1: Mapeamento no site da rede social Facebook sobre a imigração haitiana

\begin{tabular}{|c|c|}
\hline \multicolumn{2}{|c|}{ Mapeamento no site da rede social Facebook | Imigração haitiana } \\
\hline Haitïens au Brésil & $\begin{array}{l}\text { https://www.facebook, com/ ayisyenbrezil? } \\
\text { fref-ts }\end{array}$ \\
\hline Universitários haitianos que vivem no Brasil & $\begin{array}{l}\text { https://www. facebook.com/groups/ } \\
\text { b.claudy/?fref-tsEsses }\end{array}$ \\
\hline Imigração Haitiana no Rio Grande do Sul & $\begin{array}{l}\text { https://www.facebook.com/groups/ } \\
155010571310643 / \text { fref }=t s\end{array}$ \\
\hline Haitianos no Brasil (Oficial) & $\begin{array}{l}\text { https://www.facebook.com/groups/ } \\
422618107840577 /\end{array}$ \\
\hline Haitianos no Brasil & $\begin{array}{l}\text { https://www.facebook.com/groups/ } \\
388444191264376\end{array}$ \\
\hline Imigração Haitiana no Rio Grande do Sul & $\begin{array}{l}\text { https://www.facebook.com/groups/ } \\
155010571310643 /\end{array}$ \\
\hline Haitianos, Esperança Cordeiro & $\begin{array}{l}\text { https://www.facebook.com/groups/ } \\
\text { 1618017641757054/ }\end{array}$ \\
\hline Associação dos Trabalhadores Hatianos em São Paulo & $\begin{array}{l}\text { https://www.facebook.com/groups/ } \\
\text { 494845847243547/ }\end{array}$ \\
\hline Haïtiens Carioca & https://www. facebook.com/haitiencarioca \\
\hline Haitiano e Amigos de Brusque & $\begin{array}{l}\text { https://www.facebook.com/pages/Haitianos-e- } \\
\text { Amigos-de-Brusque/268377466695805 }\end{array}$ \\
\hline O que mídia não mostra do Haiti & $\begin{array}{l}\text { https://www.facebook.com/pages/O-que-a-m } \\
\text { \%C3\%ADdia-n\%C3\%A3o-mostra-do-Haiti// } \\
\underline{348040275278695 ? \text { fref-ts }}\end{array}$ \\
\hline
\end{tabular}

Fonte: $\operatorname{Cog} 0$ (2014) 
Em março de 2014, os haitianos também fizeram uso da internet para realizar uma conferência online $\mathrm{e}^{17} \mathrm{em}$ preparação à I Conferência Nacional de Migração e Refúgio (I COMIGRAR), promovida pelo governo brasileiro em São Paulo no mês de maio do mesmo ano. Iniciativa da Associação dos Imigrantes Haitianos no Brasil, a conferência levantou propostas, apresentadas posteriormente na I COMIGRAR, em torno de três eixos: igualdade de tratamento e acesso aos serviços; direitos, inserção social, econômica e popular; e abordagem de violação de direitos e meios de vinculação e proteção (COGO, 2014).

Recentemente, foi criado, ainda, o site http:// haitiaqui.com/, uma iniciativa da ONG Viva Rio. Com sede na cidade do Rio de Janeiro e atuação direta no Haiti, o site é produzido em português, francês e creole,$^{18} \mathrm{e}$ tem como objetivo, dentre outros, disponibilizar informações e oferecer orientações aos imigrantes no âmbito administrativo, assim como colaborar na capacitação e oferta de trabalho dos imigrantes. No âmbito da mesma ONG, é produzido, por imigrantes haitianos, o programa "Voz do Haiti", transmitido pela Rádio Viva Rio e apresentado em diversos idiomas.
No marco desse cenário de ocupação de espaços da mídia, debates e disputas políticas por visibilidade envolvendo imigrantes haitianos, suas redes e organizações de apoio, passamos a analisar 0 episódio da publicação da "foto roubada". Propomos, inicialmente, uma breve contextualização da imigração haitiana no Brasil na perspectiva de situar os processos de visibilidade midiática dessa imigração, para, então, reconstituir e analisar o confronto entre posicionamentos e atores que demarcou 0 episódio de publicação da imagem.

\section{Imigração haitiana no Brasil: breve contextualização}

No ano de 2010, após o terremoto que atingiu o Haiti, o Brasil começa a se consolidar como destino da imigração haitiana, a partir do ingresso de imigrantes, sobretudo pela região norte do país, mais especificamente pelas tríplices fronteiras Brasil-Peru-Colômbia e BrasilBolívia-Peru. ${ }^{19}$ Desde então, a chegada ao país de fluxos migratórios oriundos do Haiti tornouse regular e permanente, especialmente de imigrantes homens, jovens, entre os 25 e 34 anos, ainda que, a partir de 2013, seja possível observar

17 A conferência, da qual participou a coautora deste artigo, desenvolveu-se na plataforma da COMIGRAR: http://www. participa.br/comigrar/conferencia-virtual-da-associacao-dos-imigrantes-haitianos-no-brasil-aihb\#.U2QooPIdVQF.

18 Idioma oficial do Haiti, juntamente com o francês.

19 Através de rotas que incluem o deslocamento aéreo da República Dominicana ou de Porto Príncipe para o Equador e, em alguns casos, por via terrestre para o Peru. Esse trajeto é seguido de um percurso, também terrestre, até as cidades de Assis Brasil, Epitaciolândia e Brasiléia (no estado do Acre) e Tabatinga (no estado do Amazonas). Em alguns casos, os imigrantes chegam também pela cidade de Corumbá, Mato Grosso do Sul, ou, ainda, por aeroportos de grandes cidades brasileiras, como São Paulo (XIMENES; ALMEIDA, 2014, p. 31). 
também um aumento do número de mulheres, crianças e idosos.

Embora 0 terremoto seja frequentemente apontado como a principal motivação para a migração de haitianos para o Brasil, esse novo fluxo migratório não pode ser compreendido como decorrência unicamente das consequências da catástrofe que agravou as já precárias condições de sobrevivência de grande parte da população haitiana. Conforme sintetizam Cotinguiba e Pimentel, o fenômeno precisa ser lido à luz da própria constituição histórica do Haiti como uma nação diaspórica.

0 terremoto dinamizou 0 que era uma prática conhecida da sociedade haitiana, a emigração, e 0 Brasil entrou na rota migratória por fatores diversos, como a rigidez para a entrada dessas pessoas em países como Estados Unidos, Canadá, França, além do agravamento de questões étnicas com a vizinha República Dominicana. 0 discurso de uma economia em alta e a possibilidade de empregos com a realização da Copa do Mundo de 2014, somadas à relativa facilidade de transpor a fronteira do Brasil são elementos que contribuíram para essa imigração (COTINGUIBA; PIMENTEL, 2014, p.80).

Estudo realizado entre 2013 e 2014 pelo Grupo de Pesquisa Mundos do Trabalho na Amazônia, ligado à Universidade Federal do Acre (UFAC), aponta para a combinação de fatores específicos do contexto haitiano como impulsionadores dos atuais fluxos migratórios para o Brasil. A reestruturação produtiva, a globalização da economia, a precarização e a desigualdade potencializaram os desdobramentos do terremoto, contribuindo para 0 aprofundamento de epidemias, desemprego, miséria e fome, segundo a análise proposta no estudo (XIMENES; ALMEIDA, 2014, p. 31).

Estimativas produzidas por diferentes instituições vinculadas ao universo das migrações têm buscado identificar e atualizar a presença de haitianos no país ${ }^{20}$. Em sua tese de doutorado sobre as dinâmicas da mobilidade haitiana no Brasil, no Suriname e na Guiana Francesa, Joseph Handerson (2015) estima a existência no Brasil de uma população entre 35 mil e 40 mil haitianos. Em maio de 2015, o Embaixador do Haiti no Brasil afirmou que, até dezembro de $2014,{ }^{21} 53$ mil haitianos haviam ingressado no país, 20 mil dos quais regularizados através de vistos humanitários. ${ }^{22}$ Em novembro de 2015, o governo brasileiro anunciou a concessão

20 Cabe lembrar que a falta de convergência nas estimativas sobre a presença da imigração haitiana no Brasil pode ser atribuída tanto à escassez na produção de indicadores governamentais sobre a imigração internacional, como a tendência à não inclusão, nos indicadores existentes, dos imigrantes sem regularização jurídica.

21 Dados apresentados pelo embaixador do Haiti no Brasil, Madsen Chérubin, na mesa "Haiti Aqui", promovida pela ONG Viva Rio, em 21 de maio de 2015, na Universidade Zumbi dos Palmares, em São Paulo.

22 Por meio do Conselho Nacional de Imigração - CNlg, o governo brasileiro promulgou, em 12 de janeiro, a Resolução Normativa $n^{0}$ 97/201, criando um visto humanitário até então não existente na legislação brasileira. Segundo destaca Handerson (2015, p. 34), inicialmente a Resolução permitia duas leituras: a produção de uma possibilidade de legalização dos haitianos no país e, ao mesmo tempo, a restrição da chegada de novos imigrantes. 
de residência permanente a 43.781 imigrantes

haitianos que solicitaram refúgio no Brasil de janeiro de 2011 a julho de $2015 .{ }^{23}$ Entre os novos imigrantes internacionais que chegaram ao país nos últimos anos, os haitianos são o grupo migratório com maior presença no mercado de trabalho formal brasileiro (CAVALCANTI; OLIVEIRA, TONHATI, 2014), além de constituírem também os que mais vêm gerando, a partir de seu trabalho, recursos enviados em forma de remessas para 0 seu país de origem. ${ }^{24}$

Desde os primeiros fluxos de haitianos para o Brasil, desencadeados a partir de 2010, observamos, ainda, o quanto a mídia vem se ocupando, de maneira crescente, em enunciar e atribuir visibilidade a essa nova imigração, propondo e instaurando disputas em torno dos modos de vivenciar a alteridade representada pelos haitianos e impactando fortemente a constituição dos processos de inserção e cidadania de haitianos no Brasil.

Ao analisarmos, em artigo recente (COG0; SILVA, 2016), o tratamento da imigração de haitianos na mídia noticiosa brasileira nos primeiros anos da presença da diáspora haitiana no Brasil (2011-
2014) ${ }^{25}$ constatamos uma transformação no enquadramento midiático. 0 quadro de sentido mobilizado inicialmente para interpretar a imigração haitiana ao país - uma "fuga" do Haiti, da "miséria" e do "desastre" - é substituído por outro - o de "invasão haitiana" ao Brasil-, o qual passa a gerar e respaldar discursos defendendo a necessidade de controle de ingresso dos haitianos no país.

A interpretação de "invasão", porém, não era unânime nos espaços midiáticos analisados, conforme discutimos no artigo mencionado, uma vez que sentidos dessa imigração e da presença haitiana no país são disputados por diferentes atores que, nesse caso, colaboraram para impulsionar também o debate em torno da política migratória brasileira e a necessidade de sua atualização. Nessa perspectiva de disputa de atores e posicionamentos, situa-se também o caso da "foto roubada" que passamos a analisar na sequência.

\section{A "foto roubada": atores, posicionamentos e debate público}

No artigo mencionado anteriormente sobre o tratamento dado à imigração haitiana pela

Ver http://zh.clicrbs.com.br/rs/noticias/noticia/2015/11/governo-concede-visto-de-permanencia-no-brasil-a-43-781haitianos-4900150.html.

24 Considerando os 40 mil haitianos que viviam no Brasil em 2014, cerca de $80 \%$ deles economicamente ativos, 0 envio individual de remessas somaria, em um ano, um total de US\$ 76,8 milhões - $5 \%$ do total de remessas externas recebidas pelo Haiti. Ver http:// oglobo.globo.com/brasil/em-20-anos-remessa-de-dinheiro-de-trabalhadoresestrangeiros-aoexterior-aumentou-10-vezes-13749063

250 artigo baseou-se na coleta e análise de um corpus de 162 materiais midiáticos, em versão digital, sobre a imigração haitiana publicados em portais, jornais, revistas, blogs, sites de redes sociais, vinculados a organizações midiáticas públicas e privadas, assim como em publicações mantidas por instituições públicas, privadas e sem fins lucrativos. 
mídia brasileira, identificamos 10 temas ou acontecimentos a partir dos quais vem sendo tematizada a imigração haitiana que chegou ao Brasil a partir de 2010 (COGO; SILVA, 2016), dentre os quais, um dos principais faz referência à "chegada dos imigrantes haitianos ao Brasil", abordada em diferentes momentos e retomada, em termos de contextualização e memória, em várias matérias sobre a imigração haitiana produzida pela mídia brasileira no período analisado.

A "chegada" de imigrantes em barcos, a pé, ou transpondo muros e cercas em fronteiras nacionais, tem produzido, na história das migrações e, especialmente, de midiatização dessas migrações, um amplo espectro de imagens que narram, representam, visibilizam e produzem uma memória imagética contemporânea da mobilidade humana, evocando essa imigração associada especialmente a risco, ameaça, descontrole, chegada massiva, invasão.

É justamente um desses episódios - 0 da chegada à Missão Paz em São Paulo de diversos ônibus oriundos do Acre trazendo 968 imigrantes haitianos ${ }^{26}$ - que desencadeia a produção e publicação da fotografia do imigrante aqui analisada e o debate público posterior que irá se travar em torno da captura "não consentida" da fotografia e das implicações do tipo de visibilidade midiática e pública gerada por sua divulgação.

Imediatamente após a publicação, pelos jornais Agora e Folha de S. Paulo em 19 de maio de 2015, da foto do imigrante haitiano tomando banho no mictório da Missão Paz, a replicação da imagem no site da rede social Facebook pela Folh ${ }^{27}$ gerou um conjunto de ressignificações antagônicas sustentadas por diferentes argumentos. ${ }^{28} \mathrm{Em}$ um primeiro comentário, ${ }^{29}$ um leitor manifesta consternação à exposição vexatória do imigrante haitiano. A postagem, em que 0 internauta afirma que "É lamentável e triste ver o ser humano sendo tratado dessa forma", é seguida de diversos comentários com manifestações de apoio. Em direção similar, outros internautas classificam a imagem como "humilhante e degradante", expressam "compaixão pelo imigrante fotografado"; acusam a imagem de gerar "discriminação, racismo e agressão aos direitos humanos". Em outro bloco de comentários, leitores enfatizam a necessidade de proteção das fronteiras nacionais e criticam a fragilidade da política migratória brasileira, especialmente de acolhida e inserção dos imigrantes que chegam ao país. 
Há, por fim, um conjunto de comentários

de internautas que manifestam repúdio não especificamente à publicação da foto, mas à imigração haitiana de modo mais amplo, associando-a a diversos fins, tais como políticos, militares e até mesmo religiosos terroristas. Alguns deles buscam relacionar o fluxo migratório de haitianos ao Brasil com o Partido dos Trabalhadores, responsabilizando o partido pela vinda dos imigrantes, pela divulgação da imagem e da reportagem. Dentre os motivos listados pelos internautas, estaria a contribuição para as novas eleições ${ }^{30}$, sobretudo para uma ação política:

"Soldados de uma possível causa política. 0 PT estaria financiando a vinda dos imigrantes para o Brasil". ${ }^{31}$

Do total de comentários analisados, chamou a atenção 0 fato de poucos conterem questionamentos ou críticas relacionadas ao modo de produção e à divulgação da imagem pelo jornal. Uma das poucas internautas que levanta esse aspecto, Camila Coelho, a partir da indagação "Só eu que achei essa foto desumana, fotografando a pessoa tomando banho nessas condições?", recebe um pequeno número de "curtidas", (124), e gera menos discussões que as tematizações anteriores. Outro comentário chega a reiterar, inclusive, que "0 objetivo da foto é esse mesmo: chocar e chamar atenção para situação humilhante dos imigrantes haitianos", visão compartilhada por vários outros internautas. Isso sugere que o debate e a crítica em torno dos impactos da visibilidade midiática da imigração haitiana e de sua dimensão ética e política parecem ter mobilizado menos o campo de ressignificações sobre a imagem nesse espaço do Facebook.

No mesmo dia de sua publicação, a foto gerou também manifestações por parte da coordenação da Missão Paz, através da divulgação de uma "Nota de repúdio ao jornalismo sensacionalista", ressaltando as condições de vulnerabilidade que demarcam os processos de chegada e inserção dos imigrantes na cidade de São Paulo e que estariam relacionadas à ausência da família e assistência do Estado. ${ }^{32}$ A nota já acena para dimensões das relações entre estética e política que se tornariam centrais no debate instaurado posteriormente. Dimensões relativas à responsabilidade da mídia e de seus profissionais nos processos de produção de imagens públicas das migrações que chegam ao Brasil, assim como a repercussão, nos direitos humanos e cidadania dos imigrantes haitianos, de um tipo de visibilidade midiática demarcada pelo "sensacionalismo", pelo seu caráter de "invasão"

30 Cabe lembrar que os imigrantes, mesmo com residência permanente, não têm direito a voto no Brasil. Apenas os estrangeiros naturalizados possuem esse direito, da mesma forma que os portugueses que, mesmo não naturalizados, adquiriram a igualdade/gozo de direitos em relação aos brasileiros, conforme previsto na Constituição. Ver http://tre-ro.j usbrasil.com.br/noticias/2550818/0-estrangeiro-pode-votar-no-brasil

31 Disponível em: https://www. facebook.com /folhadesp/posts/1083527728355896

32 A nota foi replicada por diversos indivíduos e coletivos, como o blog Migramundo e o Jornalistas Livres. 
à vida privada do imigrante, e produzida sem a participação desses próprios imigrantes e a partir de posições assimétricas ocupadas pelo produtor ( o fotógrafo) e o fotografado (o imigrante recémchegado à cidade de São Paulo).

A Missão Paz vem a público apresentar esta nota de repúdio contra a veiculação de fotos reprováveis e sensacionalistas publicada pelos jornais "Agora São Paulo" e "Folha de São Paulo". Nenhum cidadão pode ter sua imagem violada de forma leviana e irresponsável sem que sejam realizadas diligências mínimas sobre os acontecimentos. 0s imigrantes haitianos que aqui chegam encontram-se em situação vulnerável, sem família ou apoio do governo. Algumas reportagens se aproveitam dessa situação para invadir a privacidade alheia, expondo-os sem sua autorização de forma que as imagens dessas pessoas acabam se tornando um produto a ser comercializado de maneira totalmente desumana. 0 objetivo da mídia em meio a essas crises é pressionar o Estado para tomar uma atitude, e não constranger aqueles que mais precisam de assistência. ${ }^{33}$

Em outubro de 2015, após a escolha da imagem

"Haitiano toma banho em mictório" como vencedora na categoria Fotografia do Prêmio Jornalístico Vladimir Herzog de Anistia e Direitos Humanos,${ }^{34}$ posicionamentos voltam a irromper, em espaços da internet, para conformar um novo debate que tem como foco o repúdio à concessão do prêmio à foto e o pedido de que a entidade reveja a premiação. Argumentos, já levantados na época da publicação da fotografia pelos jornais Folha de S. Paulo e Agora, são retomados tanto em uma petição pública na qual a Missão Paz questiona a concessão do prêmi $0^{35}$ como em uma carta assinada pela Organização de Haitianos de São Paulo. ${ }^{36}$

A Missão Paz expressa na petição online "indignação e repúdio sobre a foto degradante feita com um haitiano que tomava banho em condições precárias, emergenciais". No texto, a organização de apoio aos imigrantes reitera o fato da imagem publicada, a qual classifica novamente de "sensacionalista", não ter respeitado "os direitos humanos nem do haitiano fotografado, nem da comunidade haitiana como um todo".

A Missão Paz questiona, ainda, o compromisso público de um prêmio orientado aos direitos humanos que opta por uma premiação que poderia abrir precedente perigoso, ou seja, "0 do reconhecimento social de trabalhos que, inadvertidamente ou impetuosamente, não consideram a ética sobre os meios utilizados

Disponível em: http://peticaopublica.com/pview.aspx?pi=repudiofotoherzog

34 http://www.premiovladimirherzog.org.br/busca-resultado-autor-integra.asp?cd_trabalho=566

35 http://www.missaonspaz.org/\#!Indigna\%C3\%A7\%C3\%A30-e-rep\%C3\%BAdio-para-a-foto-premiadana-edi\%C3\%A7\%C3\%A30-de-2015-do-Pr\%C3\%AAmio-Vladimir-Herzog-de-Direitos-Humanos/cu8s/ $5627 f a 640 c f 2 a 9 c 7 a 2 b 943 e e$

36 A carta circulou na lista de discussão do Núcleo Interdisciplinar de Estudos Migratórios, do Rio de Janeiro (niem_rj@ yahoogrupos.com.br). 
para chegar aos seus fins" ${ }^{37}$ Ao indagar se "[...] o que mais importa: uma foto em si ou os direitos humanos do fotografado?", a petição da entidade aponta para o predomínio, entre as diretrizes de concessão do prêmio, de um critério estético (obtenção de uma imagem de qualidade técnica e jornalística, e de impacto público) e de um viés mercadológico (o imediatismo na captação e publicação da foto) sobre a preocupação com a dimensão ética e política que envolve a produção de uma imagem orientada à defesa dos direitos humanos.

Em direção similar, o argumento da organização gestora do Prêmio Vladimir Herzog, divulgado em entrevista ao blog Migramundo, parece indicar, igualmente, a relevância da técnica e da estética como critérios que pautam a escolha das fotos premiadas, ambas ancoradas na ideia de "impacto" e "denúncia". "Na categoria fotografia, são critérios específicos de premiação a qualidade técnica e enquadramento, correspondência com os fatos, 0 impacto estético da peça, inteligibilidade e grau de denúncia de violação de direitos humanos" ${ }^{38} \mathrm{~A}$ entrevista publicada pelo blog Migramundo não oferece referências sobre a compreensão que teria a entidade em relação à "correspondência da imagem com os fatos", 0 que, em certo sentido, se vincularia ao debate em torno da questão da imagem como "retrato fiel da realidade", o qual referimos anteriormente a partir das reflexões de Machado (2015).

Na mesma entrevista, a Comissão do prêmio afirma, também, que os critérios gerais para atribuição do Prêmio Vladimir Herzog se baseiam "nos valores da democracia, cidadania e direitos humanos e sociais", os quais constam no seu regulamento publicado no site www. premiovladimirherzog.org.br. Na entrevista, a Comissão lembra ainda que o julgamento do prêmio esteve a cargo, em 2015, de integrantes de um grupo de 24 profissionais de imprensa, professores e estudiosos de comunicação de vários estados do Brasil. A escolha da foto do imigrante haitiano pelo júri teria sido referendada pelos 11 membros da Comissão Organizadora do prêmio, em reunião pública realizada no dia $30 \mathrm{de}$ setembro de 2015.

0 "não consentimento" ou "não autorização" do imigrante para a captação da imagem é outro dos argumentos centrais que se destaca tanto na petição da Missão Paz como na carta elaborada pela Organização dos Haitianos de São Paulo, em que se evidencia o que já havia sido focalizado pelo outro manifesto da Missão Paz divulgado no momento da publicação da foto, em maio de 2015:

37 A esse respeito, em sua petição, a Missão Paz não deixa de reconhecer, ainda, que "0 Prêmio Vladimir Herzog tem contribuído para a formação e para a luta em prol dos direitos humanos em todo o país, cumprindo a finalidade social de informar, sensibilizar e chamar a atenção da mídia e da sociedade brasileira para importantes temáticas de direitos humanos".

38 Ver http://migramundo.com/2015/10/23/comissao-do-vladimir-herzog-defende-entrega-de-premio-a-foto-de-haitianotomando-banho 
as assimetrias de posições ocupadas, no processo de produção jornalística, pelo profissional da mídia e 0 imigrante fotografado recém-chegado à cidade de São Paulo.

\section{A Organização dos Haitianos afirma na carta que}

"conversamos com os haitianos que estavam no salão da igreja quando o fotógrafo bateu as fotos. Ele não pediu autorização. Muito mal educado, entrou no banheiro e bateu as fotos" ${ }^{39}$ No caso da Missão Paz, o manifesto chama a atenção, a esse respeito, para as condições de vulnerabilidade do imigrante recém-chegado, que o colocaria em situação desigual frente ao fotógrafo no que se refere ao conhecimento do contexto de imigração e da legislação brasileira, ao funcionamento das organizações midiáticas brasileiras, e em relação ao próprio domínio do idioma português.

\begin{abstract}
A atitude do fotógrafo, no momento de abordar 0 imigrante, expressa um flagrante desrespeito aos direitos universais da pessoa humana. Em primeiro lugar, Ronny Santos não pediu autorização ao haitiano para fazer suas fotos. 0 haitiano desabafou que estava tomando banho e o fotógrafo entrou já disparando sua máquina sem pedir qualquer autorização. Nesse momento, o haitiano tentou se esconder dentro de suas possibilidades. Pois, ele não estava em situação de se proteger, visto que não teria como imagi-
\end{abstract}

nar tal invasão por parte de um fotógrafo. Além disso, os haitianos, logo quando chegam, não falam o português e não têm conhecimento da legislação brasileira. Dessa forma, como poderia essa pessoa proteger seus direitos contra tal ato reprovável? ${ }^{40}$

Os dois documentos (petição e carta) agregam, ainda, outra informação relevante, não levantada no momento da publicação da foto, e que aludem aos desdobramentos dessa publicação na trajetória individual do imigrante fotografado. A Carta da Organização dos Haitianos em São Paulo faz referência ao fato de 0 "haitiano ter ido embora de São Paulo com muita vergonha", ao passo que o manifesto da Missão Paz revela que o haitiano "[...] desabafou conosco sobre a humilhação que sofreu. No dia seguinte, por vergonha, foi embora para outra cidade". ${ }^{41}$ A esse respeito, cabe ressaltar a ausência da voz do imigrante fotografado em todas as etapas do debate que se iniciou com a publicação da foto.

Por fim, tanto a petição da Missão Paz quanto a Carta da Organização dos Haitianos em São Paulo apontam para a questão do direito de resposta envolvendo o episódio da publicação da foto, alertando para 0 fato de esse direito ter sido solicitado quando da publicação da foto, mas

39 Trecho da carta da Organização de Haitianos em São Paulo difundida na lista de discussão do NIEM-RJ e reproduzida parcialmente pelo blog Migramundo em http://migramundo.com/2015/10/22/imagem-de-haitiano-tomando-banhoganha-premio-vladimir-herzog-de-direitos-humanos-entidades-repudiam-e fotografo-argumenta/

40 http://migramundo.com/2015/10/22/imagem-de-haitiano-tomando-banho-ganha-premio-vladimir-herzog-de-direitoshumanos-entidades-repudiam-e fotografo-argumenta/

41 http://migramundo.com/2015/10/22/imagem-de-haitiano-tomando-banho-ganha-premio-vladimir-herzog-de-direitoshumanos-entidades-repudiam-e fotografo-argumenta/ 
não concedido pelos jornais que produziram e

divulgaram a imagem ou mesmo por outras mídias.

[...] Quando saiu aquela foto, encontramos Eduardo Suplicy na igreja e denunciamos 0 que tinha acontecido. Naquela ocasião, tinha um monte de jornalistas. Denunciamos e ninguém mandou ao ar nossa denúncia. Nem na televisão, nem nos jornais. Comentamos aos fotógrafos e jornalistas "se gostariam que alguém entrasse em sua casa e fizesse fotos enquanto tomavam banho!"42

A polêmica em torno do prêmio concedido à foto do haitiano trouxe a público, também, os posicionamentos do fotógrafo do jornal Agora, Ronny Santos, autor da imagem, a partir de entrevista concedida ao blog Migramundo. 0s posicionamentos do profissional centram-se em dois aspectos: da confirmação do consentimento (autorização), por parte do imigrante, para a captação da imagem, e o da não possibilidade de identificação na imagem publicada do rosto do haitiano fotografado.

No que se refere ao processo de produção da imagem, segundo relata o fotógrafo na entrevista ao blog, "a sequência de fotografias é muito clara: ele me vê fazendo as fotos e sorri para a câmera (imagem não divulgada)"43. Em nenhum momento, ainda, de acordo com o relato de Ronny Santos, 0 imigrante teria feito menção de proibir as fotografias ou teria usado as mãos ou os braços para indicar que não queria ser fotografado, uma vez que o imigrante continuou tomando seu banho, mesmo sabendo que as fotografias estavam sendo tiradas e após a saída do fotógrafo do local.

[...] Cheguei ao local por volta das 20h. Havia um homem, brasileiro, voluntário da igreja, no portão controlando a entrada das pessoas. Passei com a máquina fotográfica por ele, que olhou e não falou nada. Já havia uma equipe de televisão no local, ou seja, o salão estava aberto à imprensa. Fiquei no local por mais de meia hora. Circulei por vários cômodos, fui visto trabalhando por voluntários e haitianos. Ninguém me abordou enquanto fazia as fotografias. Entrei em um dos banheiros e vi o haitiano se ensaboando com água do mictório. Nesse momento, não fiz fotos. 0 haitiano se escondeu atrás de uma porta expressa, clara, de que eu poderia fazer as fotos naquele momento ${ }^{44}$. Ele olhou para mim e falou alguma coisa que não entendi, e logo depois fez um sinal com as mãos facilmente compreensível: "sem problema" ou "tudo bem". E voltou a tomar banho comigo ali. Foi quando comecei a fazer as fotos ${ }^{45}$.

A confirmação sobre 0 consentimento dado pelo imigrante para a captação da imagem é o que

http://migramundo.com/imagem-de-haitiano-tomando-banho-ganha-premio-vladimir-herzog-de-direitos-humanosentidades-repudiam-e-fotografo-argumenta/

$43 \mathrm{http} / / /$ migramundo.com/imagem-de-haitiano-tomando-banho-ganha-premio-vladimir-herzog-de-direitos-humanosentidades-repudiam-e-fotografo-argumenta//

$44 \mathrm{http}: / /$ migramundo.com/imagem-de-haitiano-tomando-banho-ganha-premio-vladimir-herzog-de-direitos-humanosentidades-repudiam-e-fotografo-argumenta//

45 http://migramundo.com/imagem-de-haitiano-tomando-banho-ganha-premio-vladimir-herzog-de-direitos-humanosentidades-repudiam-e-fotografo-argumenta/ 
pauta também o posicionamento da comissão organizadora do Prêmio Vladimir Herzog, que, na entrevista ao blog Migramundo ${ }^{46}$ argumenta sobre o fato de, mesmo após as manifestações contrárias, a premiação ter sido mantida "em vista de esclarecimentos prestados por escrito pelo autor da foto, segundo o qual não houve qualquer constrangimento do fotografado, para a feitura de várias fotos". ${ }^{47}$

Outra questão diz respeito à identificação do rosto do imigrante. Na entrevista ao Migramundo, 0 fotógrafo lembra "que o jornal fez questão de não publicar fotos com o rosto do personagem nem dar qualquer identificação dele, com o objetivo de preservar sua identidade". ${ }^{48}$ A Comissão do prêmio reitera igualmente na entrevista que "não foi publicada a foto do rosto do homem que se banhava - nem seu nome - para evitar que ele se constrangesse com a publicação" ${ }^{49}$

Em contrapartida, um dos comentários de um leitor à entrevista com a Organização do Prêmio, publicada pelo blog Migramundo, levanta a possibilidade de identificação do rosto do haitiano.

Prezados membros do Prêmio Vladmir Herzog, a desculpa de que o fotógrafo respeitou a imagem e o nome do haitiano não convence. No site da folha, http://www1.folha.uol.com.br/cotidiano/2015/05/1631279-nova-onda-de-imigrantes-haitianos-causa-superlotacao-em-paroquia.shtml, é possível ver uma foto em que o rosto do haitiano está evidente. Dessa forma, não é possível concordar que o fotógrafo protegeu a imagem do haitiano na realização das imagens que levaram ao prêmio. Acredito até que 0 fotógrafo não saiba o nome do haitiano. Essa é uma falta de respeito aos direitos humanos dos haitianos e daquela pessoa em particular. Muito triste premiarem isso $0^{50}$

No percurso de captação dos materiais para nossa análise, constatamos também essa possibilidade de identificação do rosto do haitiano, especialmente no primeiro álbum (FIG. 3) publicado na versão digital da Folha de S. Paulo em 19 de maio de 2015, ilustrando a reportagem "Nova onda de imigrantes haitianos causa superlotação em paróquia". Nesse álbum (FIG. 3), em que não foi publicada a foto que seria premiada, consta uma foto do haitiano

http://migramundo.com/imagem-de-haitiano-tomando-banho-ganha-premio-vladimir-herzog-de-direitos-humanosentidades-repudiam-e-fotografo-argumenta/

$47 \mathrm{http}: / /$ migramundo.com/imagem-de-haitiano-tomando-banho-ganha-premio-vladimir-herzog-de-direitos-humanosentidades-repudiam-e-fotografo-argumenta/

$48 \mathrm{http}: / /$ migramundo.com/imagem-de-haitiano-tomando-banho-ganha-premio-vladimir-herzog-de-direitos-humanosentidades-repudiam-e-fotografo-argumenta/

49 http://migramundo.com/imagem-de-haitiano-tomando-banho-ganha-premio-vladimir-herzog-de-direitos-humanosentidades-repudiam-e-fotografo-argumenta/

$50 \mathrm{http}: / /$ migramundo.com/imagem-de-haitiano-tomando-banho-ganha-premio-vladimir-herzog-de-direitos-humanosentidades-repudiam-e-fotografo-argumenta/ 
espiando pela porta do banheiro com a cabeça ensaboada, justamente a imagem que mais permite a identificação do rosto do haitiano e à qual parece aludir justamente 0 comentário do leitor do blog Migramundo. Além disso, essa foto poderia sugerir que 0 imigrante estivesse tomando banho e, ao ver o fotógrafo, ter se escondido atrás da porta para evitar ser fotografado.
Posteriormente à premiação da foto, quando se instaura a polêmica aqui abordada, na versão digital da Folha de S. Paulo (FIG. 4), o link para acesso ao álbum fica indisponível e, quando volta a ser disponibilizado, é possível constatar que a foto do haitiano atrás da porta foi excluída e, em seu lugar, foi inserida outra imagem muito semelhante à foto premiada (a do imigrante jogando água na cabeça ensaboada com uma lata de cerveja). ${ }^{51}$

Figura 2: Álbum da versão digital da reportagem da Folha de S. Paulo com a foto do haitiano na porta

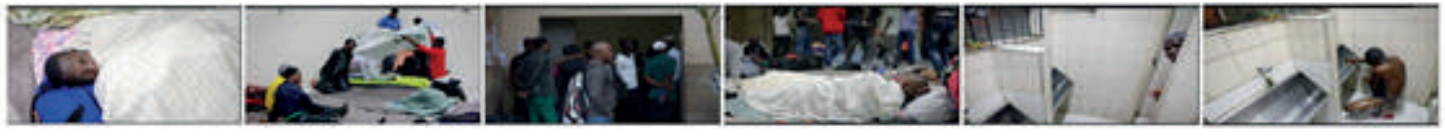

Fonte: Folha de S. Paulo, 20 de maio de 2015.

Figura 3: Álbum da versão digital da reportagem da Folha de S. Paulo com a foto substituída

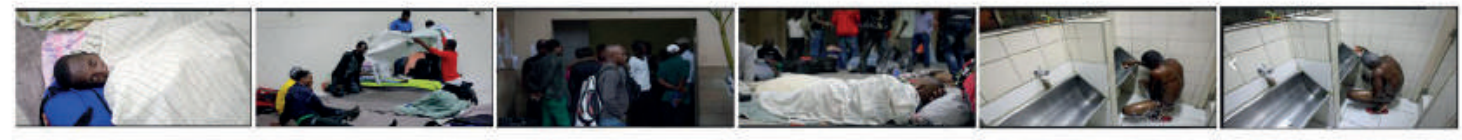

Fonte: Folha de S. Paulo, 10 de fevereiro de 2016.

\section{Considerações finais}

Se, como chama a atenção Appadurai (2005), as dinâmicas de mobilidade humana têm estado fortemente marcadas pelas articulações e tensões entre tecnicidades e imaginário, a "foto roubada", título escolhido para este artigo, parece sintetizar, a partir da análise aqui empreendida, que as barreiras físicas à mobilidade humana impostas por governos e Estados e amplamente difundidas pelas mídias têm se estendido também às representações simbólicas e à visibilidade midiática e pública atribuídas às migrações transnacionais. 
Não por acaso, no Brasil, especialmente a

partir da chegada de novos grupos migratórios, vêm assumindo preponderância, na agenda das redes migratórias e de organizações de apoio às migrações no Brasil, intervenções e debates que têm tratado de expor e problematizar modos de visibilidades das migrações ancoradas em estéticas da espetacularização, do flagrante e da denúncia, e na impossibilidade de participação dos imigrantes na construção dessa visibilidade. Além disso, os próprios imigrantes, como os haitianos aqui focalizados, têm buscado, de modo crescente, se apropriarem de espaços comunicacionais, sobretudo da internet, para mobilizar e dar visibilidade às suas demandas por cidadania e, em certo sentido, ainda que de forma fragmentada, negociar e constituir políticas próprias de visibilidade midiática.

Ambos os modos de intervenção têm contribuído para produzir questionamentos públicos em torno da apropriação, por setores da mídia brasileira, dessa nova ordem de visualidades das sociedades contemporâneas que vêm operando na construção de visibilidades compulsórias que destituem de agência os imigrantes para representá-los ora como vítimas, ora como problemas e/ou ameaças à sociedade brasileira, especialmente ao hieraquizá-los a partir de suas origens étnicas; ou, ainda, se descomprometer com a necessária contextualização de suas experiências migratórias e seus processos de cidadania no Brasil.

\section{Referências}

A PARTILHA do sensível. Entrevista a Jacques Rancière. IHU Notícias. 11 set. 2009. Disponível em: $<$ http://www.ihu.unisinos.br/noticias/25567-a-partilhado-sensivel-entrevista-com-jacques-ranciere $>$ Acesso em: 11 fev.2015

APPADURAI, Arjun. Après le colonialisme - les conséquences culturelles de la globalisation. Paris: Éditions Payot \& Rivage, 2005

BRASIL, André; MIGLIORIN, Cezar. A gestão da autoria: anotações sobre ética, política e estética das imagens amadoras. Ciberlegenda (UFF. Online). v. 1, p. 126141, 2010.

CAVALCANTI, Leonardo; OLIVEIRA, Antonio Tadeu; TONHATI, Tânia. (Orgs.). A Inserção dos Imigrantes no Mercado de Trabalho Brasileiro. Brasília: 2014. (Cadernos do Observatório das Migrações Internacionais).

COG0, Denise. Comunicação e migrações transnacionais: 0 Brasil (re)significado em redes migratórias de haitianos". Revista de Estudos Universitários. No 40, v 2, p. 233-257, dez. 2014. Disponível em: < http://periodicos.uniso.br/ojs/index. php?journal $=$ reu\&page $=$ article $\&$ p $=$ view\&path $\% \%$ $5 \mathrm{D}=2130>$ Acesso em 15 fev. 2016 .

COG0, Denise; BADET, Maria. Guia das migrações transnacionais e diversidade cultural para comunicadores - Migrantes no Brasil. Bellaterra: Institut de la Comunicación-UAB/Instituto Humanitas - Unisinos, 2013. Disponível em: https://www.academia. edu/3255909/COGO_Denise_BADET_Maria._Guia_ das_Migracoes_Transnacionais_e_Diversidade_ Cultural_para_Comunicadores_Migrantes_no_ Brasil._Bellaterra_InCom-UAB_IHU_2013. Acesso em: 15 fev 2016.C

COG0, Denise; SILVA, Terezinha. Entre a "fuga" e a "invasão" - alteridade e cidadania da imigração haitiana na mídia brasileira. Revista Famecos - 
mídia, cultura e tecnologia. v. $23, \mathrm{n}^{0} 1$, p. jan.-abril 2016. Disponível em: <http://revistaseletronicas.pucrs. br/ojs/index.php/revistafamecos/issue/view/981 > Acesso em: 31 jul. 2016.

\section{COTINGUIBA, Geraldo. C. Imigração haitiana para}

o Brasil - a relação entre trabalho e processos migratórios. 2014. 154f. Dissertação (Programa de Pós-graduação em História e Estudos Culturais da Universidade Federal de Rondônia - Unir/Porto Velho). COTINGUIBA, Geraldo. C.; PIMENTEL, Marília. L. Apontamentos sobre o processo de inserção social dos haitianos em Porto Velho. Travessia (São Paulo), v. 70, p. 99-106, 2012.

DE LA HABA, Juan; SANTAMARÍA, Enrique. Entrevista a Néstor García Canclini. 2001. Disponível em:

$<$ https://www.academia.edu/8928637/Entrevista_ a_N\%C3\%A9stor_Garc\%C3\% ADa_Canclini_ DILEMAS_DE_LA_GLOBALIZACI\%C3\%93N _HIBRIDACI\%C3\%93N_CULTURAL_ COMUNICACI\%C3\%93N_Y_POL\%C3\%8DTICA_1> Acesso em: 15 fev. 2016.

GARCIA-CANCLINI, Nestor. La sociedad sin relato. Antropología y estética de la inminencia. Buenos Aires: Katz Editores, 2010.

HANDERSON, Joseph. Diáspora. As dinâmicas da mobilidade haitiana no Brasil, no Suriname e na Guiana francesa. 2015. Tese (Programa de PósGraduação em Antropologia Social, Museu Nacional, da Universidade Federal do Rio de Janeiro - Universidade Federal do Rio de Janeiro)

\section{MACHAD0, Arlindo. A ilusão especular - uma teoria} da fotografia. São Paulo: Gustavo Gili, 2015.

NAVARRO GARCÍA, Laura. Medios de comunicación creados por inmigrantes marroquíes en España: entre la movilización social y el control político. Commons -

Revista de Comunicación Social y Ciudadanía. v. 3, n ${ }^{0}$, p. 78-110, Dic. 2014. Disponível em: < http://reuredc.uca.es/ index.php/cayp/article/view/709 > Acesso em: 15 maio 2015.
RANCIÈRE, Jacques. 0 destino das imagens. Rio de Janeiro: Contraponto, 2012.

ROCHA, Rose M. É a partir das imagens que falamos de consumo: reflexões sobre fluxos visuais e comunicação midiática. In: CASTRO, Gisela Granjeiro da Silva; BACCEGA, Maria Aparecida (Orgs). Comunicação e consumo nas culturas locais e global. São Paulo: ESPM, 2009, p. 268-293.

\section{SOUSA, José. P. Fotojornalismo. Uma introdução à} história, às técnicas e à linguagem da fotografia na imprensa. Bocc: Porto, 2002. Disponível em: http:// www.bocc.ubi.pt/pag/sousa-jorge-pedro-fotojornalismo. pdf Acesso em: 15 fev. 2016.

XIMENES, Dimas; ALMEIDA, Guillherme. Brasil de volta ao imaginário de imigrantes. Labor - Revista do Ministério Público do Trabalho. v. 2, nº 5, p. 26-32, 2014. 


\section{The "stolen photo" - media, visibility and citizenship of the Haitian immigration in Brazil}

\section{Abstract}

The article analyzes the relationship between production of images, media visibility and citizenship of the Haitian immigration in Brazil. We collected in spaces of the Internet and analyzed the positions and disputes around a specific episode involving the production and publication "without consent" of the photo of a Haitian immigrant in the newspapers Agora and Folha São Paulo. Theoretically guided by the notions of image, visibility and citizenship, the obtained results problematize the relationship between aesthetics and politics in the order of the contemporary migrations' visual images and the impact of a compulsory media visibility that deposes agency from immigrants and decontextualizes the migration processes.

\section{Keywords}

Media. Immigration. Haiti. Visibility. Ctizenship.

\section{La "foto robada" - medios}

\section{de comunicación, visibilidad}

\section{y ciudadanía de la inmigración}

\section{haitiana en Brasil}

\section{Resumen}

El artículo analiza las relaciones entre producción de imágenes, visibilidad mediática y ciudadanía de la inmigración haitiana en Brasil. Recolectamos en espacios de internet y analizamos los posicionamientos y disputas en torno a un episodio específico relacionado a la producción y publicación "no consentida" de la foto de un inmigrante haitiano por los periódicos Agora y Folha São Paulo. Orientados teóricamente por las nociones de imagen, visibilidad y ciudadanía, los resultados alcanzados problematizan las relaciones entre ética y estética el en orden de visualidades de las migraciones contemporáneas y los impactos de una visibilidad mediática compulsoria que destituye de agencia a los inmigrantes y descontextualiza los procesos migratorios.

\section{Palabras clave}

Media. Inmigración. Haití. Visibilidad. Ciudadanía. 


\section{Expediente}

A revista E-Compós é a publicação científica em formato eletrônico da Associação Nacional dos Programas de Pós-Graduação em Comunicação (Compós). Lançada em 2004, tem como principal finalidade difundir a produção acadêmica de pesquisadores da área de Comunicação, inseridos em instituições do Brasil e do exterior.

\section{E-COMPÓS I www.e-compos.org.br I E-ISSN 1808-2599}

Revista da Associação Nacional dos Programas de Pós-Graduação em Comunicação.

Brasília, v.20, n.1, jan./abr. 2017.

A identificação das edições, a partir de 2008, passa a ser volume anual com três números.

Indexada por Latindex I www.latindex.unam.mx

\section{CONSELHO EDITORIAL}

Alda Cristina Silva da Costa, Universidade Federal do Pará, Brasil Alfredo Luiz Paes de Oliveira Suppia, Universidade Estadual de Campinas, Brasil Álvaro Larangeira, Universidade Tuiuti do Paraná, Brasil Ana Carolina D. Escosteguy, Pontifícia Universidade Católica do Rio Grande do Sul, Brasil Ana Regina Barros Rego Leal, Universidade Federal do Piauí, Brasil Ana Carolina Rocha Pessôa Temer, Universidade Federal de Goiás, Brasil Andrea França, Pontifícia Universidade Católica do Rio de Janeiro, Brasil André Luiz Martins Lemos, Universidade Federal da Bahia, Brasil Angela Cristina Salgueiro Marques, Faculdade Cásper Libero, Brasil Ângela Freire Prysthon, Universidade Federal de Pernambuco, Brasil Antonio Carlos Hohlfeldt, Pontifícia Universidade Católica do Rio Grande do Sul, Brasil Arthur Ituassu, Pontifícia Universidade Católica do Rio de Janeiro, Brasil Bruno Campanella, Universidade Federal Fluminense, Brasil Cláudio Novaes Pinto Coelho, Faculdade Cásper Líbero, Brasil Carlos Eduardo Franciscato, Universidade Federal de Sergipe, Brasil Denise Tavares da Silva, Universidade Federal Fluminense, Brasil Eduardo Vicente, Universidade de São Paulo, Brasil Eliza Bachega Casadei, Escola Superior de Propaganda e Marketing - SP, Brasil Elizabeth Nicolau Saad Corrêa, Universidade de São Paulo, Brasil Erick Felinto de Oliveira, Universidade do Estado do Rio de Janeiro, Brasil Erly Vieira Júnior, Universidade Federal do Espirito Santo, Brasil Francisco de Assis, FIAM-FAAM Centro Universitário, Brasil Francisco Elinaldo Teixeira, Universidade Estadual de Campinas, Brasil Frederico de Mello Brandão Tavares, Universidade Federal de Ouro Preto, Brasil Gabriela Reinaldo, Universidade Federal do Ceará, Brasil Gilson Vieira Monteiro, Universidade Federal do Amazonas, Brasil Gustavo Daudt Fischer, Universidade do Vale do Rio dos Sinos, Brasil Igor Sacramento, Fundação Oswaldo Cruz, Brasil Itania Maria Mota Gomes, Universidade Federal da Bahia, Brasil Jiani Adriana Bonin, Universidade do Vale do Rio dos Sinos, Brasil José Afonso da Silva Junior, Universidade Federal de Pernambuco, Brasil
José Luiz Aidar Prado, Pontifícia Universidade Católica de São Paulo, Brasil Juçara Gorski Brittes, Universidade Federal de Ouro Preto, Brasil Laura Loguercio Cánepa, Universidade Anhembi Morumbi, Brasil Liziane Soares Guazina, Universidade de Brasilia, Brasil Luíza Mônica Assis da Silva, Universidade Católica de Brasília, Brasil Maria Ataide Malcher, Universidade Federal do Pará, Brasil Maria Elisabete Antonioli, Escola Superior de Propaganda e Marketing - SP, Brasil Maria das Graças Pinto Coelho, Universidade Federal do Rio Grande do Norte, Brasil Marcel Vieira Barreto Silva, Universidade Federal da Paraíba, Brasil Marcia Tondato, Escola Superior de Propaganda e Marketing, Brasil Marli Santos, Universidade Metodista de São Paulo, Brasil Márcio Souza Gonçalves, Universidade do Estado do Rio de Janeiro, Brasil Mauricio Mario Monteiro, Universidade Anhembi Morumbi, Brasil Mauricio Ribeiro da Silva, Universidade Paulista, Brasil Mauro de Souza Ventura, Universidade Estadual Paulista, Brasil Mayka Castellano, Universidade Federal Fluminense, Brasil Micael Maiolino Herschmann, Universidade Federal do Rio de Janeiro, Brasil Mozahir Salomão Bruck, Pontifícia Universidade Católica de Minas Gerais, Brasil Nísia Martins Rosario, Universidade Federal do Rio Grande do Sul, Brasil Potiguara Mendes Silveira Jr, Universidade Federal de Juiz de Fora, Brasil Raquel Ritter Longhi, Universidade Federal de Santa Catarina, Brasil Regiane Regina Ribeiro, Universidade Federal do Paraná, Brasil Roberto Elísio dos Santos, Universidade Municipal de São Caetano do Sul, Brasil Rodolfo Rorato Londero, Universidade Estadual de Londrina, Brasil Sérgio Luiz Gadini, Universidade Estadual de Ponta Grossa, Brasil Simone Maria Andrade Pereira de Sá, Universidade Federal Fluminense, Brasil Simone Maria Rocha, Universidade Federal de Minas Gerais, Brasil Suzana Reck Miranda, Universidade Federal de São Carlos, Brasil Tarcyanie Cajueiro Santos, Universidade de Sorocaba, Brasil Tatiana Oliveira Siciliano, Pontifícia Universidade Católica do Rio de Janeiro, Brasil Veneza Mayora Ronsini, Universidade Federal de Santa Maria, Brasil

\section{CONSELHO CIENTÍFICO}

Cristiane Freitas Gutfreind, Pontifícia Universidade Católica do Rio Grande do Sul, Brasil Eduardo Morettin, Universidade de São Paulo, Brasil

Felipe Costa Trotta, Universidade Federal Fluminense, Brasil Irene de Araújo Machado, Universidade de São Paulo, Brasil

\section{COMISSÃO EDITORIAL}

Eduardo Antonio de Jesus, Universidade Federal de Minas Gerais, Brasil Marco Antonio Roxo da Silva, Universidade Federal Fluminense, Brasil Osmar Gonçalves dos Reis Filho, Universidade Federal do Ceará, Brasil

\section{CONSULTORES AD HOC}

Kelly C. de Souza Prudencio, Universidade Federal do Paraná, Brasil Francisco P. Jamil A. Marques, Universidade Federal do Paraná, Brasil Tiago Quiroga F. Neto, Universidade de Brasília, Brasil

\section{EQUIPE TÉCNICA}

ASSISTENTE EDITORIAL Márcio Zanetti Negrini REVISÃO DE TEXTOS Press Revisão EDITORAÇÃO ELETRÔNICA Roka Estúdio IMAGEM DE CAPA Silas de Paula

\section{COMPÓS I www.compos.org.br}

Associação Nacional dos Programas de Pós-Graduação em Comunicação

Presidente

Edson Fernando Dalmonte

Programa de Pós-Graduação em Comunicação

e Cultura Contemporânea - UFBA

edsondalmonte@uol.com.br

Vice-presidente

Cristiane Freitas Gutfreind

Programa de Pós-Graduação em Comunicação Social - PUC-RS cristianefreitas@pucrs.br

Secretário-Geral

Rogério Ferraraz

Programa de Pós-Graduação em Comunicação

Universidade Anhembi Morumbi

rogerioferraraz@anhembimorumbi.edu.br

CONTATO I revistaecompos@gmail.com 